IRA-International Journal of Education \& Multidisciplinary Studies

ISSN 2455-2526; Vol.14, Issue 02 (February, 2019)

Pg. no. 21-25.

Institute of Research Advances

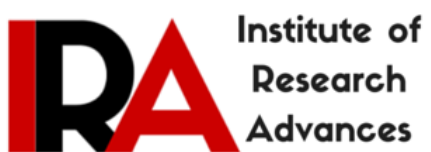

http://research-advances.org/index.php/IJEMS

\title{
The Methodology of Discourse Research from a Sociolinguistic Perspective
}

\author{
LIU Yang \\ International School, Jingchu University of Technology, Xiangshan Avenue No. 33, Jingmen City, \\ Hubei Province, P. R. China.
}

Type of Work: Peer Reviewed

DOl: http://dx.doi.org/10.21013/jems.v14.n2.p1

\begin{abstract}
How to cite this paper:
Yang, L. (2019). The Methodology of Discourse Research from a Sociolinguistic Perspective. IRA International Journal of Education and Multidisciplinary Studies (ISSN 2455-2526), 14(2), 21-25.doi: http://dx.doi.org/10.21013/jems.v14.n2.p1
\end{abstract}

(C) Institute of Research Advances.

This work is licensed under a Creative Commons Attribution-Non Commercial 4.0 International License subject to a proper citation to the publication source of the work.

Disclaimer: The scholarly papers as reviewed and published by the Institute of Research Advances (IRA) are the views and opinions of their respective authors and are not the views or opinions of the IRA. The IRA disclaims of any harm or loss caused due to the published content to any party.

Institute of Research Advances is an institutional publisher member of Publishers International Linking Association Inc. (PILA-CrossRef), USA. The institute is an institutional signatory to the Budapest Open Access Initiative, Hungary advocating the open access of scientific and scholarly knowledge. The Institute is a registered content provider under Open Access Initiative Protocol for Metadata Harvesting (OAI-PMH).

The journal is indexed \& included in WorldCat Discovery Service (USA), CrossRef Metadata Search (USA), WorldCat (USA), OCLC (USA), Open J-Gate (India), EZB (Germany) Scilit (Switzerland), Airiti (China), Bielefeld Academic Search Engine (BASE) of Bielefeld University, Germany, PKP Index of Simon Fraser University, Canada. 


\section{ABSTRACT}

Systemic Function Linguistics is a mainstream thought of sociolinguistic research and can be a theoretical model and the research methodology of linguistic research. Based on a combination of Systemic Function Linguistics and Sociological Discourse Analysis, this study adopts the thematic progression, ideational function, and interpersonal function to analyze discourses which come from daily used information, to dissect the information to see the discourse structure, in order to advantage the discourse contrastive research for further studies.

\section{Keywords: Sociolinguistics, Thematic Progression, Ideational Function, Interpersonal} Function

\section{Introduction}

\subsection{The Analytical Model of Discourse Structure}

The discourse analysis of systemic function linguistics is fulfilled by the thematic structure model in details. In discourse analysis, the general concept is not about the subject and the predicate, but about the theme and rheme. This concept was proposed by the representative of functional school V. Mathesius, and then it was developed by Firbas, F. Daněs and Halliday, etc.

Mathesius firstly proposed the syntactic analysis method of Actual Division. From the view of Actual Division, he divided the sentence into two parts, theme (the beginning of a description) and rheme (the essence of a description). The beginning of a description is always a given information which transmits weakly an information; however, the essence of a description generally expresses the new information, which owns the strong information transmission.

Danĕs firstly proposed the concept of thematic progression. He elevated the theme and rheme analysis to the discourse analysis, explained the relationship between theme and rheme of a sentence in the discourse as thematic progression, and contributed it to an effective method to do the discourse analysis. He studied the cohesion regular of theme and rheme between all kinds of sentences in the discourse, and thought that the discourse information structure is up to the progression of theme and rheme, concluded with five thematic progression model, such as simple linear thematic progression model, constant thematic progression model, derived patterns of thematic progression model, constant rhematic progression model, converse linear thematic progression model.

Halliday has adopted the Prague school's theme and rheme concept and put them into the three meta-function of systemic function linguistics as the textual function, formed the thematic structure analysis model. The theme is at the beginning of the sentence, the starting point of information and communication, and the rheme is after the theme, the essential information in expression. The theme can be classified into the textual theme, interpersonal theme, topic theme according to a different function. The textual theme is on the top of a sentence, and the words or sentences are coherent, such as, actually, I just knew the situation too; interpersonal theme is at the beginning of a sentence, clarifying the speaker's attitude, will and mood and so on, such as, to me, it's better to let him go, I think he's fine; topical theme is the top of the sentence, the object of the speaker's expression, such as he has left.

Halliday also classified the theme into a simple theme, multiple theme and clausal theme according to the complex degree in the internal theme structure. Simple theme presents the conceptual function, and it's an independent entity, which cannot be separated into small function units; multiple themes was a theme formed by many parts as textual part, interpersonal part and conceptual part, they are called textual theme, interpersonal theme and topical theme; clausal theme is a theme with a short sentence. (HU Zhuanglin, ZHU Yongsheng, ZHANG Delu, 1991)

Based on the need of discourse function contrastive study, this thesis synthesizes related research results, concludes into four basic models of discourse analysis: constant rheme model, simple linear model, constant rheme model, converse linear model. We will develop the descriptions in the next chapter in details.

\subsection{The Analytical Category of Discourse Function}

Halliday defines the meta-theory meaning of discourse function from the beginning of systemic function linguistics. From the sociolinguistic position of the relation between language and society, he proposed three meta-function thoughts of language, ideational function, interpersonal function and textual function. The ideational function is the semantic system to express the concept. It includes the experiential function and logic function, and it's presented by language categories such as transitivity, polarity and voice; interpersonal function is to present the linguistic relational function, presented by linguistics category such as mood, modality, key and 
so on; textual function means that the speaker expresses the text with complete thought and unified context, and it forms the discourse matching on context.

The three functions of discourse are highly relational, and it presents the integrity, coherence and cohesion. Because, "the basic units in the real utilization are not the same as grammatical units such as words or sentences, but it expresses relatively a text with complete though. Both of the above functions can be achieved by speakers who organize them into a discourse. This is the textual function. Therefore, we can understand the textual function analysis category as textual function reflects a function that speakers form a complete discourse matching with the context; we recognize the language to see whether it belongs to the standard of discourse category, which are integrity, coherence and cohesion; the trinity relations of textual function, ideational function and interpersonal function.

In fact, the discourse function thought of Halliday experienced two great development stages, initial stage and mature stage.

During the initial period, the textual function was called the relevance function or enabling function, the linguistic means such as thematic system, information system and cohesion system are surely the major presentation form of discourse function, therefore it differentiates the other two meta-functions. But at the same time, Halliday emphasized that interactivity is the essential characteristic of discourse, and discourse is the communication medium between social membership, and it's not the selected product or result of traditional linguistics. According to this thought, discourse is a dynamic process and linguistic structural means constructing the social fact by social members, transmitting and strengthening social conscious. Based on this meaning, discourse function can be identified as causative function. Discourse is realized by sentence, but not to be composed by a sentence in nature.

After the 1990s, Halliday utilized the grammatical metaphor theory as an essence, contribute to adjust and revise the original theoretical system, further establish the linguistic philosophy thought, advance to discourse function thought more complete and mature. The so-called "grammatical metaphor" is the main mechanism of language to construct the reality, and it has an essential distinction with ideational function. If we define an ideational function as a referential property function, states the relationship between language and the objective world; textual function is not referential, what it wants to explain is the interior relationship of language, it pays more attention to the sociosemiotic position, and the construction of linguistic interpersonal meaning and textual meaning. Based on this meaning, grammatical metaphor theory and textual function analysis form the footstone of Halliday's linguistic philosophy thought.

So far, some discourse analysis research is limited to the description of the linguistic characteristics as thematic structure, information structure and cohesion and so on. Few of them discuss the further relationship between language and social meaning of discourse. It's seen as the misunderstanding or deviation of discourse function thought of systemic function linguistics.

\section{Thematic Progression}

What interests us here is this question: where do themes come from, and how do they relate to other themes and rhemes in the text? The following are some of the main patterns of thematic progression:

1. Constant Theme Progression

Constant Theme Progression means the T is identical in a sequence of sentences.

$\mathrm{T} 1 \rightarrow \mathrm{R} 1$

$\mathrm{T} 2(=\mathrm{T} 1) \rightarrow \mathrm{R} 2$

$\mathrm{T} 3(=\mathrm{T} 1) \rightarrow \mathrm{R} 3$

For example, The Miami Heat (T1) was formed in 1988 (R1). The team (T2) is going to win the final game of NBA (R2). They (T3) have three All-Stars, James, Wade and Bosh (R3).

2. Constant Rheme Progression means the $\mathrm{R}$ is identical in a sequence of sentences.

$\mathrm{T} 1 \rightarrow \mathrm{R} 1$

$\mathrm{T} 2 \rightarrow \mathrm{R} 2(=\mathrm{R} 1)$

$\mathrm{T} 3 \rightarrow \mathrm{R} 3(=\mathrm{R} 1)$

For example, Washington Wizards (T1) is an NBA team (R1). Chicago Bulls (T2) is an NBA team (R2). Toronto Raptors (T3) is an NBA team (R3).

3. Simple Linear Progression 
Simple Linear Progression means the R (rheme) in the previous sentence becomes the T(theme) of the next sentence.

$\mathrm{T} 1 \rightarrow \mathrm{R} 1$

$$
\begin{aligned}
& \mathrm{T} 2(=\mathrm{R} 1) \rightarrow \mathrm{R} 2 \\
& \mathrm{~T} 3(=\mathrm{R} 2) \rightarrow \mathrm{R} 3
\end{aligned}
$$

For example, I (T1) just met Bryant (R1). Bryant (T2) has finished training with James (R2). James (T3) is now working for Miami Heat (R3).

4. Converse Linear Progression

Converse Linear Progression means each $\mathrm{T}$ becomes the R of the next sentence. (ZHANG Yinglin, 2006)

$\mathrm{T} 1 \rightarrow \mathrm{R} 1$

$\mathrm{T} 2 \rightarrow \mathrm{R} 2(=\mathrm{T} 1)$

$\mathrm{T} 3 \rightarrow \mathrm{R} 3(=\mathrm{T} 2)$

For the example, the game (T1) was fantastic (R1), but the fans (T2) didn't like it (R2). The grand hall (T3) contains thousands of fans. They did like the grand hall (R3).

\section{Ideational Function}

The ideational metafunction focuses on six processes, namely, material process, mental process, relational process, verbal process, behavioural process and existential process. After reading a significant resource of the thesis of learning the theory, we know that most of them emphasize the first four process on sports news, which determines that sports news try to originate the facts which can attract readers to know the information and meaning of discourse.

Material process means the action to do, to happen in one sentence, or describing one circumstance, such as moving, changing, pushing, pulling, jumping, running, flying and so on. The writers try to describe the facts which directly get the reader to know the original scene.

The mental process is the process of the physical sense of a human being, such as touching, seeing, hearing, feeling, imagining, and so on. Halliday differentiates as perception, as seeing, hearing; affection, as disliking, loving; cognition, as feeling, thinking. It's a way of reaction and perception.

The relational process is a process of being such as be, become, have, and so on, to show the relationship between two objects.

The verbal process is like a conversation between the interviewer and interviewee, the specific words are like saying, speaking, talking, telling, describing, making a speech, and so on. Any verbal words collect with starting to make an original conversation.

The behavioral process is a process that behaving. It contains both physical and psychological process, just as the medium of material and mental process such as watch, wave, etc. Existential process means existence decides the conscious, and the objects exist to reflect on the human mind, such as there be, exist, and so on.

\section{Interpersonal Function}

Polarity in the interpersonal function expresses the two definite directions which are yes or no, the modality is used between the ways of polarity. Chinese has the impression of modest and implicit, and their way of writing is indirect, so in this part, we discuss mainly the modality of interpersonal function to see the modality of Chinese English sports news and unveil the other side of sociolinguistic features of Chinese English.

As we know, the interpersonal function is the communication between the speaker and listener, writer and reader, etc. Both the speaker and writer want to communicate efficiently by making adaptive language to adapt to the context so that the listener and reader can understand the thought of the former. By analyzing and comparing Chinese English sports news and American English sports news, we can distinguish the modality of interpersonal function in the two kinds of discourses, and recognize the discourse features of the modality of Chinese English sports news.

The modality means to choose an adaptive word between yes and no, such as maybe, possibly, could be, should be, etc. We can divide the item of different probability into four parts.

1. Different probability, such as possibly, probably, certainly.

2. Different frequency, such as sometimes, usually, always.

3. In English grammar, we express the probability and frequency in three ways (1) Finite modal verbs as, 
will, must. (2) The probability and frequency of modal adverb as, probably, usually, always. (3) Usage at the same time as we probably will not leave. He certainly should come.

4. The variation to count the modal operators, with the values of high, median and low. A high value such as must, need, ought to, have to; of course, surely, certainly, definitely, absolutely, completely, always, never; required, determined; sure, believe, certain. Median value like, will, would, shall, should; probably, usually, often; supposed, expected, keen; low value such as may, can, could, might; maybe, perhaps, possibly, sometimes; allowed to, willing to; guess, feel, in my opinion,. (HU Zhuanglin, 2005)

\section{Conclusion}

To study the contrasting discourse, we must utilize the specific linguistic theory to contrast the discourse structure and function, and integrate into different kinds of discourse analysis under a suitable theoretical structure, to reveal the sociolinguistic significance.

Systemic function linguistics is a theory to study the language and linguistic research that are based on social contextual background, strengthen the close relation between a system of language form and language significance, and pay attention to the inner relation of discourse analysis and sociolinguistic theory. The core of systemic function linguistics has broken through the serious boundary of applied linguistics and sociolinguistics, which broaden the sociolinguistic research area to benefit the theory itself. Then, this research is followed by this basic thought.

This study analyses the thematic structure for the constant theme progression, simple linear progression, constant rheme progression, and converse linear progression models. Furthermore, we study the discourse function for the material process, relational process, the verbal process, and the modality of low value, median value and high value to presents the sociolinguistic features of different information.

\section{References}

[1]. Halliday, M. A. K. An Introduction to Functional Grammar [M]. London: Edward Arnold, 1994.

[2]. Halliday, M. A. K. and Hasan, R. Cohesion in English [M]. London: Longman, 1976.

[3]. Halliday, M. A. K. The Linguistic Sciences and Language Teaching [M]. London: Longman, 1964.

[4]. HU Zhuanglin, LIU Runqing, LI Yanfu. Linguistics A Course Book [M]. Peking: Peking University Press, 1988.

[5]. HU Zhuanglin, ZHU Yongsheng, ZHANG Delu. A Survey of Systemic Functional Grammar [M]. Peking: Peking University Press, 2005.

[6]. HU Zhuanglin. The Cohesion and Coherence of Discourse [M]. Shanghai: Shanghai Foreign Language Education Press, 1998.

[7]. ZHANG Yinglin. Discourse Analysis [M]. Wuhan: Central China Normal University Press, 2006.

[8]. ZHU Yongsheng, YAN Shiqing, MIAO Xingwei. An Introduction to Function Linguistics [M]. Shanghai: Shanghai Foreign Language Education Press, 2004. 